\title{
PkM Pendampingan Dan Pengabdian Masyarakat Terdampak Gempa \& Tsunami Di Wilayah Sulawesi Tengah
}

\author{
Fransiskus Irwan Widjaja ${ }^{1}$, Daniel Ginting ${ }^{2}$, Ronald Sianipar ${ }^{3}$, Sabar M \\ Hutagalung ${ }^{4}$, Winson Simmamora ${ }^{5}$, Benteng MM Purba ${ }^{6}$ \\ 1, 2,3,4 Prodi Teologi, STT REAL Batam \\ ${ }^{5,6}$ Prodi PAK, STT REAL Batam \\ *irwanwidjaja.fiw@gmail.com
}

Abstract:

Indonesia is part of the Ring of Fire region, an area filled with volcanoes. One of the biggest disasters in 2018 was the earthquake, Liquidfaksi and Tsunami in the Central Sulawesi area. The earthquake \& tsunami covered Palu City and Donggala Regency, Parigi Moutong Regency, Sigi Regency, Central Sulawesi Province. The lack of volunteers and the large number of victims moved the PKM STT real to go directly to the handling of victims of the earthquake and tsunami. As well as serving the affected communities who live in tents and are separated from their extended family, which causes high levels of stress. The community service team provides assistance and provides short solutions. Insights on Pastoral Counseling Services, Healing Inner Wounds, Trauma, Praying, serving the sick, building temporary houses, sending PAK teachers and Alumni to teach at the earthquake site.Access to information is still lacking, making the PKM team prepare short observations and research to distribute assistance and services as needed. The purpose of this activity is to provide understanding, knowledge and assistance. Volunteer groups in carrying out practices and activities to help friends in refugee camps together with other institutions. The implementation method for this community service program is assisting families and helping the learning of children who cannot go to school. From the results of the evaluation with the PKM team, training and mentoring activities are very useful because in addition to knowing the level of stress, it helps overcome social problems that are affected and how to handle them.

Keywords: Assistance, Training, earthquake victims

Abstrak

Indonesia bagian dari wilayah rings of Fire, daerah yang di penuhi gunung api. Salah bencana yang terbesar di tahun 2018 adalah gempa bumi, Liquidfaksi dan Tsunami di daerah Sulawesi Tengah. Gempa \& tsunami meliputi Kota Palu dan Kabupaten Donggala, Kabupaten Parigi Moutong, Kabupaten Sigi, provinsi Sulawesi Tengah. Minimnya relawan dan banyakknya korban menggerakkan PKM STT real untuk terjun langsung untuk penanganan korban gempa dan tsunami. Serta melayani masyarakat terdampat yang tinggal di tenda tenda dan terpisah dari keluarga besar, masyarakat yang mengakibatkan tingginya tingkat stress. Team pengabdian masyarakat melakukan pendampingan dan memberi solusi solusi singkat. Wawasan mengenai Pelayanan Pastoral Konseling, Penyembuhan Luka Batin, Trauma, Mendoakan, melayani yang sakit, membangun rumah sementara, mengutus guru guru PAK dan Alumni untuk mengajar di lokasi gempa. Akses informasi yang masih kurang, membuat team PKM mempersiapkan pengamatan dan penelitian singkat untuk menyalurkan bantuan dan pelayanan sesuai yang di butuhkan Tujuan kegiatan adalah untuk memberikan pemahaman, pengetahuan dan bantuan. Kelompok relawan dalam melakukan praktek dan aktivitas membantu teman teman di pengungsian Bersama sama dengan Lembaga lainnya. Metode pelaksanaan pada program pengabdian masyarakat ini, yaitu pendampingan keluarga keluarga dan membantu pembelajaran anak anak yang tidak dapat sekolah. Dari hasil evaluasi dengan team PKM, pelatihan dan pendampingan kegiatan sangat berguna karena selain mengetahui tingkat stress, membantu mengatasi masalah masalah social yang terdampak dan penanganannya.

Kata kunci: Pendampingan, Pelatihan, korban gempa 


\section{PENDAHULUAN}

Wilayah Indonesia yang luas terdiri dari banyak pulau, tercatat ada 17.504 pulau dan berada pada jalur gempa bumi dan gunung berapi. ${ }^{1}$ Keadaan tersebut mengakibatkan Indonesia rawan terhadap berbagai bencana alam. Di Indonesia saja, berdasarkan data dari aplikasi Magma Indonesia, Pusat Vulkanologi dan Mitigasi Bencana Geologi Kementerian Energi dan Sumber Daya Mineral(ESDM), per Sabtu (29/12/2018) ini saja ada 68 gunung api aktif di Indonesia. ${ }^{2}$

Peristiwa bencana alam merupakan persitiwa yang tidak mudah dihindari dan diperkirakan secara tepat. Dampak dari musibah bencana bisa berupa korban jiwa, harta benda, kerusakan infrastruktur, lingkungan sosial, dan gangguan terhadap tata kehidupan serta penghidupan masyarakat yang telah mapan sebelumnya.

Gempa Bumi 7,4 Skala Richter yang mengakibatkan terjadinya Likuefaksi (Pencairan Tanah), diikuti dengan Tsunami dipantai Barat Pulau Sulawesi pada tanggal 28 September 2018, pukul 18.02 WITA. Getaran gempa bumi dirasakan di Kabupaten Donggala, Kota Palu, Kabupaten Parigi Moutong, Kabupaten Sigi, Kabupaten Poso, Kabupaten Tolitoli, Kabupaten Mamuju bahkan hingga Kota Samarinda, Kota Balikpapan, dan Kota Makassar. Gempa memicu tsunami hingga ketinggian 5 meter di Kota Palu memicu evakuasi massa dengan kerusakan total 66.390 rumah hancur, 2.045 tewas (menurut BNPB per 10 Oktober 2018) 632 luka-luka 100+ orang hilang, 16.732 penduduk mengungsi. Berdasar pendataan yang telah dilakukan, bencana Palu mengakibat kan kerugian 18,48 Triliun Rupiah, ${ }^{3}$ secara material. Angka kerugian dan kerusakan tersebut meliputi sektor permukiman, infrastruktur, sosial, ekonomi dan lintas sektor.

Korban bencana alam ini mengalami trauma karena kematian orang yang disayang, harta benda, runtuhnya tempat tinggal dan ladang sawah yang menjadi sumber penopang kehidupan mereka selama ini. Kondisi di pengungsian yang di bawah standar kehidupan menambah beban mental jiwa semakin terhimpit. Banya nya waktu yang terbuang di pengungsian, berdampak meningkatnya pengungsi yang terindikasi gangguan psikologis.

\section{Permasalahan Lapangan}

Korban bencana tsunami, gempa dan likuifkasi di perhadapkan dengan keadaan dan kondisi yang sangat kompleks, baik secara fisik, psikis maupun sosial. Pemenuhan kebutuhan menjadi persoalan utama: persoalan fisik, kebutuhan sandang; makan, minum, tempat tinggal, kesehatan, dan pendidikan. Rusak dan tidak tersedia fasilitas umum, sosial dan sanitasi serta lingkungan yang buruk menimbulkan ketidak nyamanan serta dapat menjadi sumber penyakit. Harta benda lenyap seketika menyebabkan korban jatuh miskin, ditambah lenyapnya sumber mata pencaharian, lengkap penderitaan pengungsi. Perpisahan dengan anggota keluarga diakibatkan kematian, khususnya orang yang sangat dicintai ataupun yang berperan penting dalam keluarga, seringkali mengakibatkan timbulnya perasaan khawatir, ketakutan bahkan trauma yang berkepanjangan. Bantuan berupa materi yang didapat dari berbagai sumber mungkin dapat memenuhi kebutuhan fisik para korban bencana, tetapi masalah yang dihadapi belum tentu terselesaikan. Kehilangan orang yang dicintai, tempat tinggal, harta benda, sawah, atau ternak yang menjadi mata pencarian, dapat mengakibatkan gangguan kejiwaan dan trauma hebat.

Program "Palu Mission dan Real Care" yang digagas oleh STT REAL Batam adalah bagian dari program Pengabdian Masyarakat STT REAL Batam yang peduli akan penderitaan sesama untuk melaksanakan tri dharma perguruan tinggi. PKM kali ini: Pelayanan Pastoral Konseling, Penyembuhan Luka Batin, Trauma, Mendoakan, melayani yang sakit, membangun rumah sementara,

${ }^{1}$ Badan Pusat Statistik, "Luas Daerah Dan Jumlah Pulau Menurut Provinsi,” BPS - Statistics Indonesia, accessed September 5, 2014, https://www.bps.go.id/statictable/2014/09/05/1366/luas-daerah-dan-jumlah-pulaumenurut-provinsi-2002-2016.html.

${ }^{2}$ Mona Kriesdinar, "Mengenal Sabuk Cincin Api, Si Pembangkit Gempa, Gunung Api Dan Tsunami Di Indonesia," TribunJogja.Com (Yogyakarta, 2018), https://jogja.tribunnews.com/2018/12/29/mengenal-sabukcincin-api-si-pembangkit-gempa-gunung-api-dan-tsunami-di-indonesia.

${ }^{3}$ Christiyaningsih, "Gempa Dan Tsunami 2018 Palu Timbulkan Kerugian Rp 18,48 T," Republika.Co.Id (Palu, May 2019), https://nasional.republika.co.id/berita/nasional/umum/pqwoxz459/gempadan-tsunami-2018-palu-timbulkan-kerugian-rp-1848-t. 
mengutus guru guru PAK dan Alumni untuk mengajar di lokasi gempa. Adapun kegiatan pengabdian ini diadakan tanggal $21 \mathrm{~s} / \mathrm{d} 26$ Oktober 2018.

\section{Sumber Dana}

Usulan dana pengabdian diajukan pada SekolahTinggi Teologi REAL Batam, sumbangan siswa, bantuan gereja, sumbangan pribadi. Diharapkan melalui program pastoral konseling, konseling trauma dan mendoakan serta membantu membangun rumah sementara dan mengutus guru guru alumni STT Real Batam, baik jurusan PAK maupun Theologi. Di harapkan bantuan total secara holistic dapat meringankan beban penderitaan masyarakat sekaligus menjangkau yang belum "percaya" dengan kasih Kristus. Pelayanan ini juga mendukung program pemerintah dalam masa tanggap darurat dan masa pemulihan. Pelayanan yang di berikan dapat menyentuh dan membangun nilai-nilai kehidupan, sehingga dapat memperlengkapi warga secara jasmani dan rohani.

\section{Tujuan Kegiatan}

Tujuan Memberi bantuan baik secara fisik, maupun secara spiiritual

a. Membantu warga yang kemalangan dengan memberi Truma healing

b. Memberikan semangat dan motivasi bagi warga jemaat yang kemalangan

c. Membantu secara finansial, obat obat, makanan, pakaian, kesehatan

d. Membangun rumah sementara

e. Mengutus guru guru untuk mengajar di sekolah maupun di tenda

\section{Manfaat Kegiatan}

Kegiatan PKM STT Real Batam, untuk membantu kelompok masyarakat yang terdampak musibah di mana korban bencana memiliki kebutuhan hidup yang harus terpenuhi. Kebuthan hidup yang tidak terpenuhi dalam kurun waktu yang lama dapat menimbulkan masalah sosial. Dimana manusia secara individu dan masyarakat tidak dapat melaksanakan fungsi sosialnya. Manfaat dari kegiatan ini adalah mengembalikan kebutuhan dasar para pengungsi dan korban gempa. Kebutuhan dasar manusia menurut Elizabeth Nicolds ${ }^{4}$ di dalam tulisan C. Rusmiyati dan E. Hikmawati2012 meliputi:

a. Rasa aman (security) dari lingkungan manusia, alam serta gangguan penyakit.

b. Kasih sayang (affection) dari keluarga dan masyarakat lingkungannya.

c. Meraih cita-cita (achievment) ditengah kondisi kehidupan yang sesuai dengan yang diinginkan.

d. Penerimaan (acceptance) eksistensi diri ditengah masyarakat sekitarnya.

LP Getubig dan Schmidt ${ }^{6}$ menjelaskan bahwa individu ataupun kelompok masyarakat dapat dikatakan aman secara sosial (sosially secured) apabila kebutuhan hidupnya terpenuhi dalam aspek:

a. Pendapatan tetap dan cukup (adequate and stable income)

b. Kesehatan (health care)

c. Asupan gizi cukup (good nutrion)

d. Rumah tempat tinggal (shelter)

e. Pendidikan (education)

f. Air bersih (clean water)

g. Sanitasi (sanitation)

h. Penyantunan anak dan lanjut usia (child and old age care)

Sumarnonugroho ${ }^{7}$ menyatakan kebutuhan dasar hidup manusia meliputi:

a. Hidup

\footnotetext{
${ }^{4}$ N. Elizabeth, A Primer of Social Case Work (New York: Columbia University Press, 1965).

${ }^{5}$ Chatarina Rusmiyati and E Hikmawati, "Penangan Dampak Sosial Psikologis Korban Bencana Merapi," Sosioinforma: Kajian IPermasalahan Sosial dan Usaha Kesejahteraan Sosial 17, no. 2 (2012): 97110.

${ }^{6}$ I P Getubig et al., Rethinking Social Security: Reaching out to the Poor (Kuala Lumpur: Asian and Pacific Development Centre and Deutsche Gesellschaft für Technische Zusammenarbeit (GTZ), 2012).60

${ }^{7}$ Sumarnonugroho, Sistem Intervensi Kesejahteraan Sosial (Yogyakarta: Hanindita, 1984).
} 
b. Merasa aman

c. Penghargaan atas eksistensi dirinya

d. Melakukan pekerjaan yang disenangi.

Selanjutnya aspek kebutuhan dasar hidup manusia yang dijelaskan Globe ${ }^{8}$ tentang teori Abraham Maslow adalah:

a. Melakukan pekerjaan yang disenangi.

b. Kebutuhan fisik seperti makan, minum, dan udara untuk bernafas.

c. Rasa aman.

d. Menyayangi dan disayangi

e. Penghargaan diri

f. Aktualisasi diri

Kebutuhan dasar manusia bisa terpenuhi dengan mudah apabila alam dan lingkungan manusia mendukung, yang artinya keadaan alam dalam kondisi normal atau sedang tidak terjadi bencana.

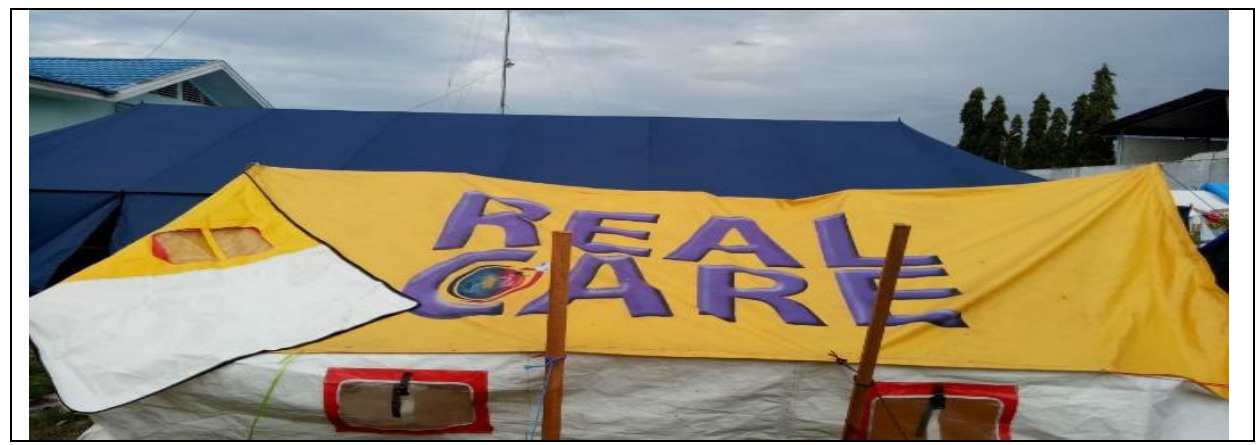

Gambar 1. Pemasangan Posko Pendampingan Bencana

Sebaliknya apabila alam dan lingkungan dalam keadaan yang tidak normal (bencana) maka kebutuhan dasar manusia itu tidak terpenuhi, maka supaya dapat terpenuhinya kebutuhan dasar, manusia memerlukan bantuan dari pihak lain. Dalam hal ini manusia sebagai pengungsi memerlukan bantuan orang lain agar tetap dapat bertahan hidup di tempat pengungsian.

\section{Tahapan Kegiatan}

Tahap-tahap yang dilaksanakan dalam kegiatan ini:

a. Tahap Sosialisasi, tahap ini dimulai dengan mengenal karakter dari kelompok sasaran sehingga akan memudahkan dalam melaksanakan program yang direncanakan agar individuindividu dalam kelompok pada program ini mampu bangkit dan percaya diri pulih.

b. Tahap Pendampingan pada tahap ini, kelompok didampingi untuk dapat menjalankan kegiatan dengan pastoral care di sertai dengan pengertian

c. Tahap pemantauan pasca kegiatan, yang bertujuan untuk melihat pertumbuhan pemulihan para pengungsi dan korban

\section{Metode Penelitian}

Berdasarkan masalah yang dikemukakan tersebut di atas, maka Tim pengabdian kepada masyarakat (abdimas) melakukan penelitian singkat. Penelitian ini bersifat deskriptif kualitatif, dilaksanakan di tempat pengungsian. Pengumpulan data dilakukan dengan wawancara lisan dampak sosial psikologis korban bencana. Observasi tentang kondisi dan analisa dokumen dan pemetaan yang terkait dengan kondisi wilayah dan jumlah korban. Selanjutnya data yang terkumpul dianalisis secara deskriptif kualitatif. Langkah Analisa sebagai berikut:

1. Pada tahap pertama untuk pemecahan masalah terbatasnya pengetahuan pengungsi, simpang siur berita yang di terima dan kekuatiran dan ketakutan yang meningkat serta kecemasan yang berlebihan. Untuk meningkatkan pengetahuan maupun percaya diri mereka, serta untuk meningkatkan pemberdayaan diri sehingga ada kegairahan dalam bentuk pemberdayaan maka Tim

\footnotetext{
${ }^{8}$ Frank G. Globe, Mazhab Ketiga: Psikologi Humanistik Abraham Maslow (Yogyakarta: Kanisius, 1987).
} 
merencanakan pendekatan berupa Ceramah/kotbah, Konsultasi dan mendoakan.

2. Tahap kedua untuk meningkatkan ketinggalan pelajaran sekolah anak anak yang ada, alumni dan calon guru guru di tempatkan di tempat tempat pengungsian, mengajar dan mendampingi para keluarga keluarga yang anak anak nya tidak dapat melanjutkan sekolah akibat runtuhnya bangunan sekolah.

3. Tahap ketiga, untuk membangun sikap untuk meningkatkan percaya diri, bagi mereka yang kehilangan pekerjaan dilakukan dengan diskusi, tanya jawab dan mencari solusi berbagai kendala saat itu yang sering mereka alami berkaitan dengan kondisi di tempat pengungsian.

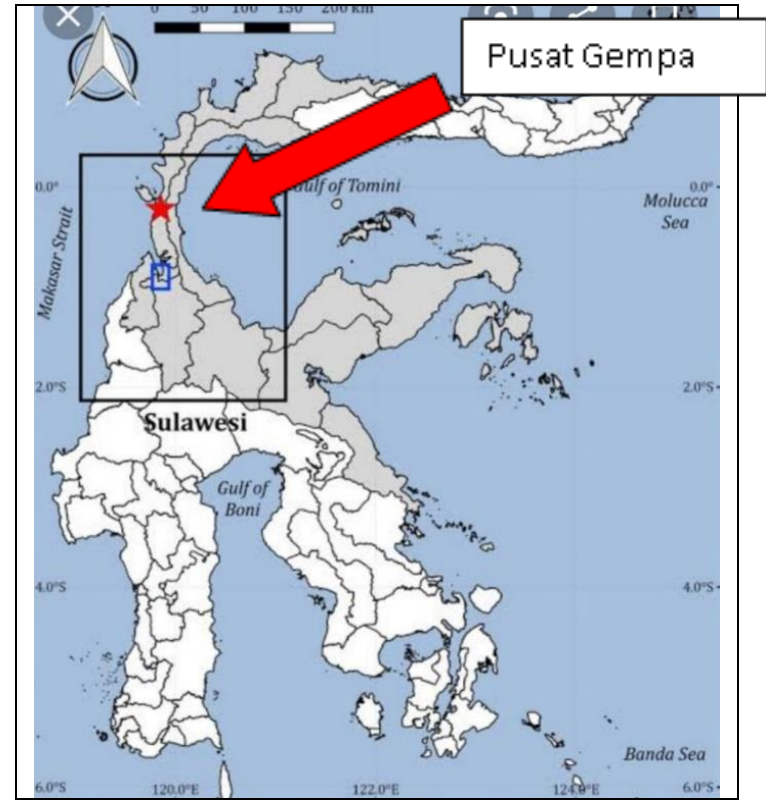

Gambar 2. Wilayah Pusat Gempa

\section{Metode Pelaksanaan}

\begin{tabular}{|c|c|c|c|c|c|c|}
\hline \multirow{2}{*}{ No } & \multirow{2}{*}{ Uraian Kegiatan } & \multicolumn{5}{|c|}{ Waktu 2018-2019 } \\
\hline & & Okt & Nov & Des & Jan & Feb \\
\hline 1 & Pendataan lokasi Gempa & & & & & \\
\hline 2 & Dropping kebutuhan pokok & & & & & \\
\hline 3 & Drop Team Medis \& Konselor & & & & & \\
\hline 4 & Droping Tenaga Pendidik & & & & & \\
\hline 5 & Penarikan seluruh team & & & & & \\
\hline
\end{tabular}

Berdasarkan pengamatan dan wawancara observasi lapangan yang telah diuraikan diatas, bahwa terdapat permasalahan sebagai berikut:

Beberapa permasalahan yang dihadapi korban bencana yaitu:

1. Kehilangan rumah kediaman.

2. Kehilangan pekerjaan karena kerusakan lahan pertanian dan hancurnya tempat usaha.

3. Berpisah dengan anggota keluarga biasanya ayah atau suami. Memilih untuk tetap tinggal di rumah dengan alasan menjaga harta benda atau tetap bekerja sebagai petani, berkebun atau peternak.

4. Pemenuhan kebutuhan dasar berupa makan, minum, tempat tinggal sementara atau penampungan, pendidikan, kesehatan dan sarana air bersih yang tidak memadai.

5. Terganggunya pendidikan anak-anak yang tidak bisa sekolah karena kerusakan sarana dan prasarana sekolah.

6. Timbulnya penyakit-penyakit (batuk, flu) ataupun penyakit menular diare karena kurangnya kebersihan di lingkungan dan tempat penampungan.

7. Terganggunya peranan dan fungsi keluarga terhapat individu disebabkan banyaknya keluarga yang tinggal bersamaan ditempat pengungsian atau penampungan. 
8. Pudarnya harga diri dan kapabilitas yang baik sebagai individu maupun sebagai keluarga sebab di tempat pengungsian mereka mendapatkan belas kasihan dari pihak lain dan bahkan seringkali menjadi tontonan.

9. Terkendalanya implementasi fungsi dan peran sosial dalam komunitas hingga aktivitas adat atau budaya yang tidak dapat terlaksana di tempat pengungsian.

10. Timbulnya perasaan jenuh terhadap waktu pegungsian yang tidak pasti, perasaan tidak berdaya, ketakutan dan bahkan perasaan putus asa menghadapi kemungkinan bencana yang tidak mungkin dihindari (tidak dapat melawan kehendak Tuhan). Akhirnya mengakibatkan marah, stres, dan frustasi terhadap keadaan yang serba tidak menentu, trauma, putus asa, merasa tidak berdaya dan ketidakpastian terhadap masa depannya.

11. Menjadi tidak realistis dan mencari kekuatan supra natural untuk mengantisipasi terjadinya musibah. Kekecewaan spiritual yaitu kecewa pada Tuhan karena diberi ujian atau hukuman bahkan cobaan kepada orang-orang yang merasa dirinya sudah melaksanakan ibadah sesuai ajaran agama $^{9}$

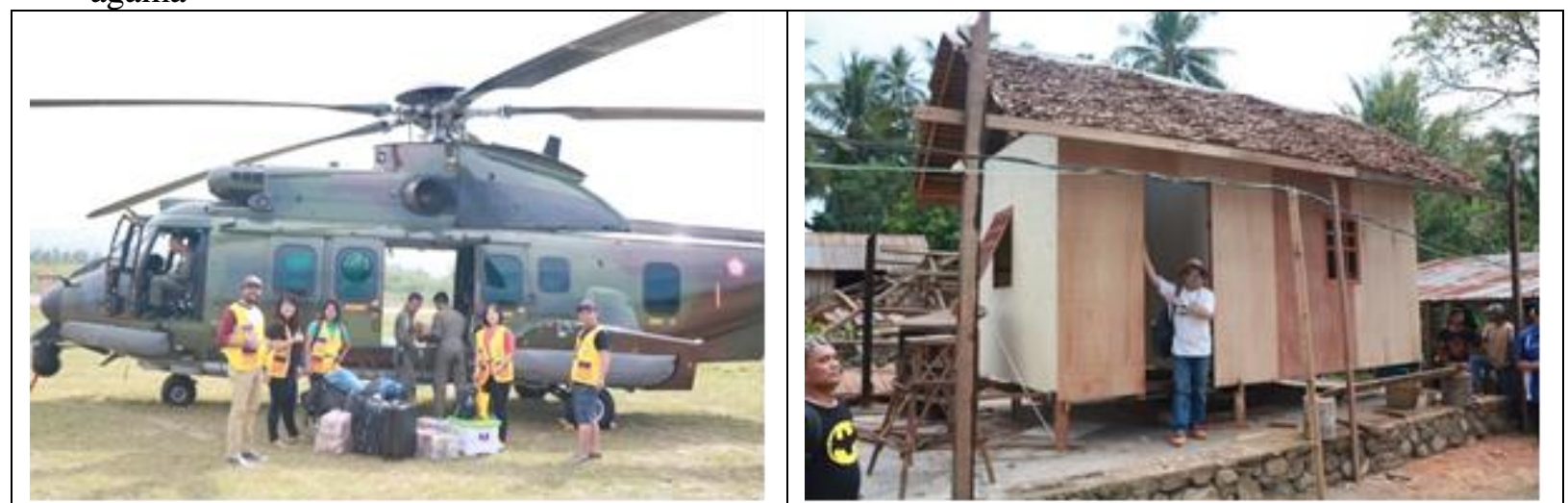

Gambar 3. Team Relawan siap di angkut ke tempat yang membutuhkan \& Membangun rumah sementara

\section{Hasil Pembahasan}

Dari kegiatan pengabdian masyarakat melalui PKM. Dari 24 orang anggota team yang terdiri dari dosen, guru alumni, medical dokter yang di bagi tiga group, secara maksimal mengerjakan hal hal di lapangan di dapati sebagai berikut:

Penanganan Korban Bencana Palu yang diiringi dengan Pelayanan sosial PKM STT Real Batam yang melibatkan relawan dan Yayasan terhadap pengungsi di tenda tenda merupakan tindakan yang sama di lakukan pemerintah ataupun kelompok swasta bersekala internasional, nasional maupun lokal. Tujuan aksi sosial untuk memberikan perlindungan hukum, ketentraman, pemenuhan kebutuhan pangan, pakaian, shelter, fasilitas kesehatan, bantuan administratif kependudukan, reintegrasi dengan keluarga dan relokasi. Menurut Allen Pansus dan Anne Minahan dalam Surjono ${ }^{10}$, pelayanan sosial ditujukan untuk membantu masyarakat yang menghadapi persoalan sehari-hari dalam keluarga, anak anak yang mendapat kendala belajar di sekolah, orang yang menghadapi kesulitan untuk mendapatkan pekerjaan guna menghidupi dirinya dan berbagai kondisi kehidupan traumatis seperti kedukaan, perpisahan dengan keluarga, menderita suatu penyakit dan masalah keuangan sebagai penopang hidup. Demikian juga Sukamdi dalam Surjono, ${ }^{11}$ yang di kutip dari C. Rusmiyati dan E. Hikmawati ${ }^{12}$ mengemukakan bahwa aksi bantuan kepada pengungsi adalah untuk:

a. Perlindungan, secara khusus kepada perempuan, anak-anak dan lanjut usia.

b. Memfasilitasi supaya dapat kembali ke pemukiman asal perantauan atau lokasi baru.

c. Membereskan sumber masalah yang mengakibatkan pengungsian agar dikemudian hari tidak

\footnotetext{
${ }^{9}$ Chatarina Rusmiyati and Hikmawati, "Penangan Dampak Sosial Psikologis Korban Bencana Merapi."

${ }^{10}$ Gunanto Surjono, Uji Coba Konsep Model Penyelesaian Masalah Pengungsi Perantau Di Tempat Penampungan Sementara Daerah Asal (Yogyakarta: B2P3KS, 2004).

${ }^{11}$ Ibid.

${ }^{12}$ Chatarina Rusmiyati and E Hikmawati, "Penangan Dampak Sosial Psikologis KorbanBencana Merapi," Informasi 17, no. 02 (2012): 97-110.
} 
terjadi masalah pengungsian yang serupa.

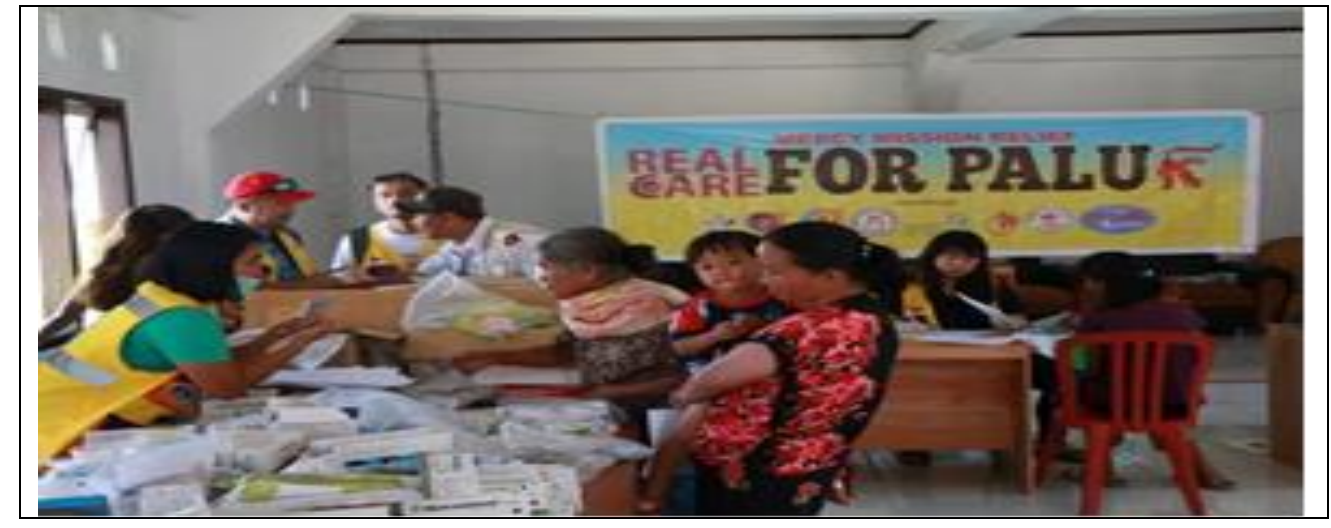

Gambar 4. Team Relawan Memberikan Pengobatan Gratis kepada masyarakat terdampak gempa

Rusmiyati dan E. Himawati ${ }^{13}$ mengutarakan bahwa pemberdayaan pengungsi meliputi tiga hal pokok, yaitu:

a. Pendidikan dan pembangkitan kesadaran. Pendidikan dan pembangkitan kesadaran mencakup tiga unsur yaitu:

1) Pendidikan formal terutama bagi pengungsi anakanak agar tidak terlalu tertinggal pendidikan anak-anak lain yang bukan pengungsi,

2) Pendidikan informal untuk pengungsi dewasa yang bisa berlangsung setiap waktu dengan tujuan untuk menanamkan nilai, pengetahuan, keterampilan, akses informasi usaha ekonomis produktif dengan memanfaatkan sumber alam, manusia dan sosial disekitarnya. Dengan pendampingan, bimbingan, dan konsultasi maka pendidikan informal dapat dilakukan.

3) Pendidikan non-formal yang bertujuan terhadap pemberdayaan hukum, demokrasi, ekonomi produktif, advokasi pemenuhan hak azasi kehidupan dan kekerasan gender.

b. Pelibatan Kebijakan dan Perencanaan Pemerintah

Dalam Widjaja, ${ }^{14}$ untuk dapat mempengaruhi kebijakan pemerintah dalam hal ini, masyarakat dapat menilai dan merasakan suatu kehidupan yang lebih baik; misalnya: tersedianya lapangan pekerjaan, perbaikan gizi, mutu pendidikan yang meningkat, stabilitas keamanan dan berkurangnya tingkat kemiskinan. Pengambil keputusan mempunyai kompetensi dalam sektor keamanan, sistem ekonomi, penyediaan akses lembaga keuangan, fasilitas informasi, kesehatan, kesejahteraan sosial, layanan administrasi kependudukan, dan penyediaan sarana sekolah formal. Kebijakan dan perencanaan pemerintah berperan untuk mencegah persoalan yang berlanjut, seperti stres berkepanjangan, kekecewaan, frustrasi, perilaku negatif, pemiskinan, pembodohan, dan ketertinggalan sebagai dampak dari lama mengungsi tanpa intervensi dari pihak pengambil kebijakan pemerintah.

Hal ini dimaksudkan untuk mencegah peluang terjadinya masyarakat yang dimarginalkan, sosial cost atau generation lost.

c. Aksi Sosial Politik

Dalam masyarakat pengungsi sendiri, aksi ini dijalankan dengan menjunjung tinggi prinsip partisipasi, dimulai dari penyusunan rencana, identifikasi masalah, penetapan skala prioritas, tujuan, implementasi dan pemantauan, serta evaluasi akhir dalam proses rehabilitasi pengungsi. Program pemberdayaan bagi pengungsi tidak dapat tercapai secara maksimal apabila dilaksanakan

13 Ibid.

${ }^{14}$ Fransiskus Irwan Widjaja, "Peran Gereja Terhadap Kehidupan Politik Di Wilayah Kepulauan Riau," Real Didache 1, no. 2 (2016): 117-140. 
di tempat pengungsian, akan lebih baik apabila dilaksanakan di tempat asal apabila memungkinkan atau di tempat baru yang lebih aman. Pemberdayaan masyarakat pengungsi tidak cukup dilakukan pemerintah saja, tetapi harus melibatkan pihak lain seperti swasta, lembaga lembaga social serta masyarakat lingkungan di mana pengungsi berada, baik secara perorangan maupun terorganisir yang bekerja sama atas nama kemanusiaan. Tunner dalam Surjono mengutarakan bahwa tidak ada satu bagian penanganan yang ditekankan dan didominasikan (overstressed and dominated) dalam penanganan pengungsi tetapi semua bagian harus berkolaborasi saling mengisi kompleksitas kebutuhan pengungsi. ${ }^{15}$ Unsur pelayanan sosial pokok yang harus dilakukan bersama seperti pemenuhan kebutuhan makan, kesehatan, pakaian, keamanan/pendidikan, relokasi dan perlindungan hukum. Sedangkan unsur penunjang meliputi publikasi, simpati masyarakat lingkungan dan semangat hidup dari pengungsi sendiri.

Langkah yang dilakukan dalam upaya penanganan dampak sosial psikologis korban bencana Palu antara lain:

a. Pendampingan, untuk mengupayakan kepastian mengenai pemenuhan kebutuhan dasar pengungsi secara layak dan memadai.

b. Pastoral care. Keluarga yang kehilangan kepala keluarga mengakibatkan seorang istri atau ibu mengambil alih peran kepala keluarga sekaligus pencari nafka, oleh karena itu keluarga-keluarga pengungsi yang kehilangan kepala keluarganya perlu memperoleh dukungan khusus. Agar masa peralihan fungsi tersebut dapat berlangsung dengan baik diperlukan dukungan dari berbagai pihak termasuk didalamnya pengertian, dukungan dan partisipasi dari semua anggota keluarga. Sehingga fungsi keluarga dapat kembali pulih dan stabilisasi peran keluarga dapat dicapai.

c. Setiap Individu yang mengalami stress atau trauma atas bencana, yang mengakibatkan kehilangan harta benda ataupun anggota keluarganya akan mendapatkan layanan konseling. Masyarakat yang direlokasi memiliki rasa ketidak puasan dan ketidak berdayaan dengan keadaan dan kondisi baru yang berbeda dengan aktifitas yang meraka lakukan sebelum bencana sehingga tidak sedikit yang menolak untuk direlokasi. Perasaan-perasaan tersebut kerap mengakibatkan gangguan psikis, seperti kecemasan dan insomnia, stres, frustrasi dan selalu ada peluang timbulnya aksi sosial atau konflik. Pendampingan pastoral yang dijalankan yaitu penyingkapan perasaan-perasaan negatif yang diteruskan dengan pembelajaran sederhana tentang cara membangun perasaan-perasaan yang positif dan berkolaborasi dengan kelompok untuk mengumpulkan data-data hal-hal positif yang dapat dibuat di daerah yang baru dan melakukan rancangan kegiatan.

d. Membangun partisipasi. Di barak-barak pengungsian (dapur umum, latihan keterampilan dan kegiatan lain), perlu adanya pelibatan pengungsi dalam berbagai kegiatan. Hal tersebut untuk memalingkan perasaan-perasaan tidak produktif, dan dalam menyusun rencana pemulihan.

e. Mediasi dan fasilitasi relokasi dibarengi dengan penyuluhan kepada masyarakat di tempat tujuan yang baru supaya dapat menerima kehadiran para pengungsi yang direlokasi ke daerah mereka. ${ }^{16}$

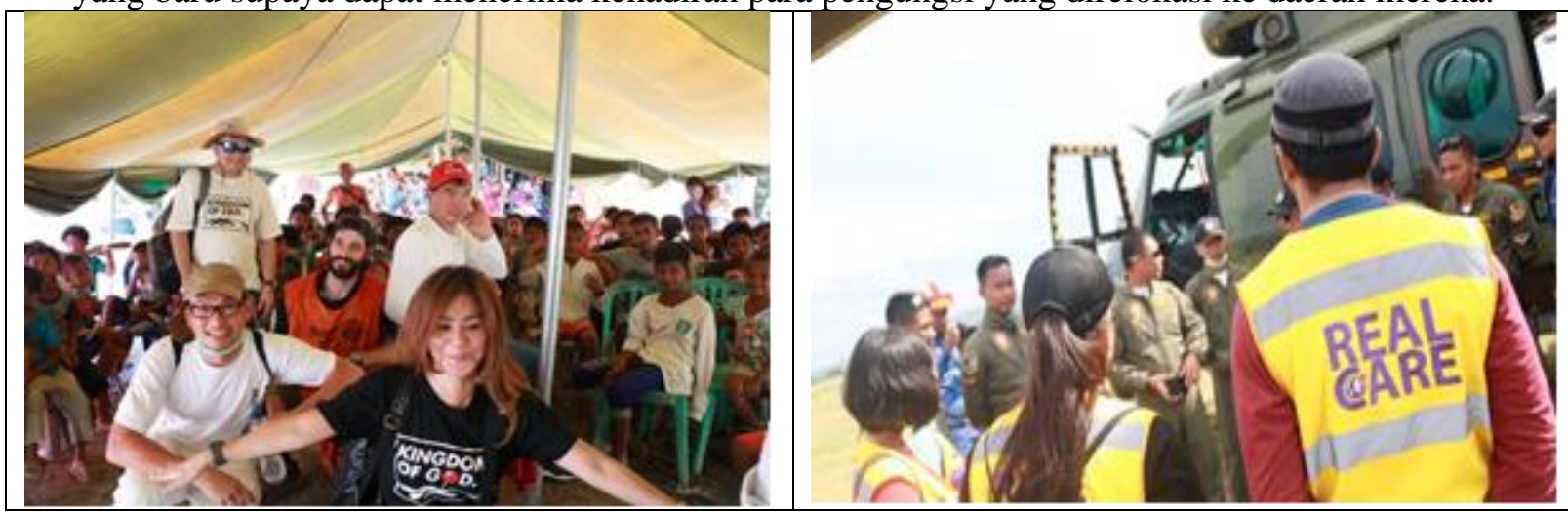

Gambar 5. Team Relawan PKM siap di relokasi ke daerah yang membutuhkan

${ }^{15}$ Surjono, Uji Coba Konsep Model Penyelesaian Masalah Pengungsi Perantau Di Tempat Penampungan Sementara Daerah Asal.

${ }^{16}$ Rusmiyati and E Hikmawati, "Penangan Dampak Sosial Psikologis KorbanBencana Merapi." 


\section{KESIMPULAN}

Kegiatan pengabdian masyarakat PKM Pendampingan Dan Pelatihan dalam penanganan Korban bencana, khususnya pengungsi memerlukan berbagai kebutuhan agar dirinya dapat bertahan hidup dan bangkit kembali semangatnya untuk hidup bermasyarakat. Untuk itu, hal-hal di bawah ini perlu di perhatikan:

1. Penanganan Dampak Sosial Psikologis.

Permasalahan nyata yang dialami korban bencana antara lain kondisi dalam penampungan atau pengungsian, tercerai berainya tatanan keluarga baik selama proses pelarian maupun pengungsian, melemahnya semangat kemasyarakatan karena padatnya kampung-kampung pengungsian

2. Pemenuhan kebutuhan fisik

Kebutuhan fisik merupakan masalah utama yang memerlukan bantukan kepada korban bencana, seperti makan, minum dan tempat tinggal yang aman. Pentingnya pemenuhan kebutuhan fisik ini dikarenakan penduduk yang tinggal di daerah rawan bencana harus segera menyelamatkan diri menuju ke tempat aman atau barak pengungsian yang sudah disediakan pemerintah.

3. Pemenuhan kebutuhan psikis

Perasaan Sedih yang dialami oleh pengusing yang disebakan karena kehilangan keluarga yang mereka sayangi, harta benda, rumah, matapencaharian, dan merasa asing di tempat pengungsian dapat mengakibatkan timbulnya gangguan psikologis. Sehingga selain kebutuhan fisik, hal yang tidak kalah penting adalah pemenuhan kebutuhan psikis.

4. Pemenuhan kebutuhan social

Pengungsi yang berada di pengungsian harus rela tinggal bersama di barak pengungsian dengan berbagai macam karakter orang. Situasi dan kondisi kehidupan yang mereka alami di pengungsian sering memunculkan perasaan kecewa dan putus asa bahkan frusterasi karena ketidakjelasan dengan nasib mereka

\section{Saran}

Saran yang di usulkan:

1. Dalam memberikan bantuan kepada korban bencana (pengungsi) perlu, melakukan analisa kebutuhan agar tepat sasaran yaitu sesuai dengan kebutuhan, baik jenis maupun jumlahnya,

2. Perlu kerja efisien dan efektif, supaya kerja bisa akurat dan tepat sasaran. Agar overlapping job bisa di minimalis

3. Melakukan pemberdayaan agar masyarakat siaga akan bencana yang mungkin terjadi setiap waktu, sehingga dapat meminimalisir resiko bencana.

\section{DAFTAR PUSTAKA}

Chatarina Rusmiyati, and E Hikmawati. "Penangan Dampak Sosial Psikologis Korban Bencana Merapi." Sosioinforma: Kajian IPermasalahan Sosial dan Usaha Kesejahteraan Sosial 17, no. 2 (2012): 97-110.

Christiyaningsih. "Gempa Dan Tsunami 2018 Palu Timbulkan Kerugian Rp 18,48 T." Republika.Co.Id. Palu, May 2019.

https://nasional.republika.co.id/berita/nasional/umum/pqwoxz459/gempa-dan-tsunami-2018palu-timbulkan-kerugian-rp-1848-t.

Elizabeth, N. A Primer of Social Case Work. New York: Columbia University Press, 1965.

Getubig, I P, Sönke Schmidt, Asian and Pacific Development Centre, and Zusammenarbeit Deutsche Gesellschaft für Technische. Rethinking Social Security : Reaching out to the Poor. Kuala Lumpur: Asian and Pacific Development Centre and Deutsche Gesellschaft für Technische Zusammenarbeit (GTZ), 2012.

Globe, Frank G. Mazhab Ketiga: Psikologi Humanistik Abraham Maslow. Yogyakarta: Kanisius, 1987.

Kriesdinar, Mona. "Mengenal Sabuk Cincin Api, Si Pembangkit Gempa, Gunung Api Dan Tsunami Di Indonesia." TribunJogja.Com. Yogyakarta, 2018. https://jogja.tribunnews.com/2018/12/29/mengenal-sabuk-cincin-api-si-pembangkit-gempagunung-api-dan-tsunami-di-indonesia. 
Rusmiyati, Chatarina, and E Hikmawati. "Penangan Dampak Sosial Psikologis KorbanBencana Merapi.” Informasi 17, no. 02 (2012): 97-110.

Statistik, Badan Pusat. "Luas Daerah Dan Jumlah Pulau Menurut Provinsi." BPS - Statistics Indonesia. Accessed September 5, 2014. https://www.bps.go.id/statictable/2014/09/05/1366/luas-daerahdan-jumlah-pulau-menurut-provinsi-2002-2016.html.

Sumarnonugroho. Sistem Intervensi Kesejahteraan Sosial. Yogyakarta: Hanindita, 1984.

Surjono, Gunanto. Uji Coba Konsep Model Penyelesaian Masalah Pengungsi Perantau Di Tempat Penampungan Sementara Daerah Asal. Yogyakarta: B2P3KS, 2004.

Widjaja, Fransiskus Irwan. "Peran Gereja Terhadap Kehidupan Politik Di Wilayah Kepulauan Riau." Real Didache 1, no. 2 (2016): 117-140. 